\title{
Debate e Investigación \\ Historicidad, turismo y política urbana: exploración de la relación entre los tres factores
}

G.J. Ashworth

Universidad de Groningen (Holanda)

Este artículo formó parte de las comunicaciones presentadas en el Congreso Internacional sobre Desarrollo Turístico Integral de Ciudades Monumentales que se celebró en Granada durante los dias 19 a 22 de febrero del año 2002 y reunió, con la ayuda de organismos internacionales y nacionales, a los más destacados expertos acerca de cuestiones de indudable interés: turismo patrimonial, de ciudad, monumental, cultural... Entre las aportaciones, valedoras de un desarrollo turístico válido y razonable, destacaba la contribución del profesor de la Universidad de Groningen, G.J.Ashworth, quien componia una estructura de tres factores: historicidad, turismo y politica urbana, para comprender globalmente las relaciones existentes entre gestión y patrimonio. La explicación teórica de este sistema tripartito y de las conclusiones que genera son de nuevo reproducidas para participar ahora con voz propia en el debate planteado.

\section{Palabras clave}

\section{Ciudades históricas}

Turismo cultural Patrimonio cultural Áreas urbanas Gestión Desarrollo local

\section{¿A dónde voy?}

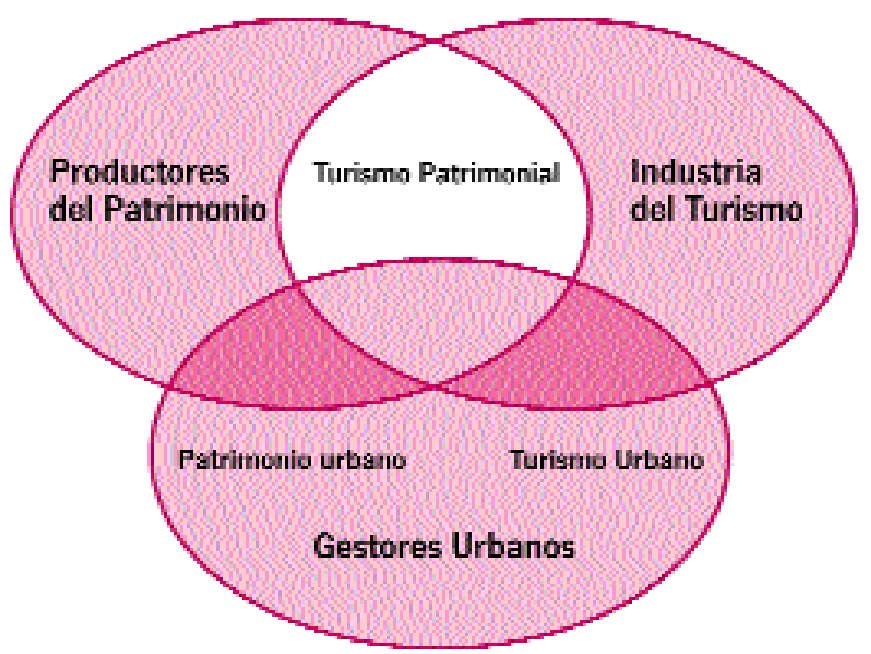

Ilustración 1: Los socios

\section{La tarea}

Este trabajo pretende afrontar una tarea más compleja y desalentadora que la de hacer observaciones sobre la combinación de los tres factores (Historicidad, Turismo y Politica Urbana). Es lo suficientemente simple para describirlo en un diagrama como el de la ilustración 1, en la que el campo de interés es el área de superposición entre los tres fenómenos. El abandono del sistema a favor de un planteamiento sintético, aunque esencial para nuestros intereses en esta conferencia, tiene un punto débil. Intenta relacionar los resultados de tres procesos bastante independientes, cada uno de los cuales ha sido perseguido por distintas personas para lograr distintos fines sin examinar la naturaleza de dichos procesos en sí, que serian demasiado espaciarlos en el consumo e invalidarían la sintesis. El tríptico formado por una actividad, -el turismo, un atributo de lugares y objetos, -la historicidad- y una gestión de procesos, -la política urbana-, debe ser visto en su conjunto para que emerja su significado. Pero la evolución y las características singulares de cada colaborador en dicha gestalt no se pueden examinar como si dicha descomposición destruyera en vez de esclarecer. La elección debe hacerse por tanto entre superficialidad e irrelevancia: este trabajo ha optado por la primera opción.

\section{Suposiciones, excusas y advertencias}

La tarea se hace más manejable y comprensible mediante algunas definiciones de trabajo y suposiciones limitadoras. La historicidad es una atributo contemporáneo generalmente expresado mediante designaciones, interpretaciones y productos de patrimonio. Aunque la donación pueda proceder de un pasado ima- 
$058-059$

Debate

e Investigación

Historicidad, turismo y

política urbana: exploración

de la relación entre los tres

factores

PH42 - Febrero 2003

ginario e incluso pretenderse para un futuro imaginario, el presente es el único punto válido de referencia. El turismo es una forma de recurso derivada de una historicidad acomodada y lo importante es que no debe ser constantemente reiterada. De forma similar, el turismo es una de las funciones que acogen las ciudades y una actividad que realiza la gente. En casi todas partes de la mayoría de las ciudades durante la mayor parte del tiempo y de hecho para la mayor parte de la gente, es relativamente poco importante comparado con otras funciones y preocupaciones. Por último, el turismo juega un papel económico mayor en algunas ciudades que en otras y algunas ciudades son más conscientes de su historicidad que otras. La ciudad turistico-histórica no es una categoría particular y extraña de emplazamiento urbano. Ninguna ciudad del mundo carece de historia y por tanto de potencial patrimonio y todas las ciudades han recibido y acomodado por lo menos a un visitante en algún momento. Ya sea la ausencia del pasado o de la función turística o ya sea su presencia monopolística podrían dar como resultado un espacio distinto al urbano. El tercer elemento, la política urbana, tiene muchas metas, instrumentos y prácticas que no tienen importancia para la historicidad o el turismo. De hecho en raras ocasiones es el turismo-historicidad el único objetivo de la política urbana o el instrumento para obtener distintos objetivos.

\section{Historia breve de una relación}

La relación entre los tres componentes tiene en sí misma una historia dividida en tres fases consecutivas reconocibles, aunque las ciudades individuales pueden entretenerse más tiempo, incluso indefinidamente, en una sola fase o incluso satisfacerse en una serie recurrente de asuntos promiscuos.

\section{Primer amor en un ménage à trois}

Inicialmente, la historicidad, el turismo y la política urbana, encuentran su satisfacción en la compañía mutua. Los principales representantes de cada una de las tres partes involucradas, a saber, los productores del patrimonio, la industria del turismo y los gestores de los lugares locales disfrutan de "las ganancias IIovidas del cielo" que parecen derivarse de los otros. El enamoramiento mutuo se explica fácilmente. Los productores del patrimonio buscan tanto nuevas fuentes de apoyo económico para sus caras actividades como una justificación para su existencia continuada que los recibos se encargan de demostrar. Los turistas Ilenan los museos vacíos, las salas de conciertos, las galerias y monumentos, asi como las cajas de sus tiendas de souvenirs. En segundo lugar, la industria del turismo está en constante búsqueda de nuevos productos para satisfacer una demanda que es cada vez más selectiva, inconstante, dependiente de la moda y sofisticada. El patrimonio parece ofrecer una fuente ubicua, gratis, de acceso libre, flexible e infinitamente embalable para la producción de productos muy cambiantes para este mercado.
Por último, los gestores de los lugares buscan nuevas fuentes de bienestar económico y nuevos instrumentos para conseguir estrategias de desarrollo económico o social. El turismo patrimonial ofrece unos ingresos rentables en el uso de una fuente existente y gratuita con los beneficios adicionales de identidad local reforzada, cohesión social e imágenes de mercado favorables. Dicho modelo de ganancias inesperadas asume que los recursos de patrimonio ya existen con otros fines y se utilizan por consiguiente para crear productos y venderlos en nuevos mercados turísticos con impactos locales beneficiosos que parecen rendir unos resultados totalmente positivos. También se asume que el mismo producto de patrimonio sea consumido tanto por el turismo como por los mercados locales, que el consumo extra no disminuya o dañe los recursos, que un aumento en un grupo de consumidores no lleve a la disminución de los otros y que los beneficios y los costes acumulados sean experimentados en porcentajes iguales por cada una de las partes implicadas.

Como ninguno de estos supuestos es necesariamente exacto y es probable que esto sea cada vez más evidente para las tres partes, el modelo y por tanto la relación, se hace cada vez más insostenible excepto en circunstancias muy excepcionales.

\section{El comienzo de la desilusión y el conflicto}

El reverso de estos supuestos de armonía automática, y probablemente una reacción hacia los mismos, es la idea de conflicto automático entre los fenómenos, los mercados y las metas irreconciliables. Los conceptos principales son: la explotación de los recursos y el manejo gratuito aunque no está siempre claro quién explota a quién y a costa de quién. Los productores de patrimonio se aprovechan cada vez más del desarrollo turístico como explotadores, degradadores y contaminantes irresponsables de los recursos patrimoniales. El turismo se contempla como una de las causas principales del daño físico, la intrusión visual y lo peor de todo, del daño psíquico de la "autenticidad", "integridad" o simplemente la "calidad" de los paisajes culturales, las ciudades, los edificios, los objetos y las representaciones (ver las numerosa polémicas como las de Horne, 1984; Hewison, 1987; Turner \& Ash, 1976; Cheng, 1990). Mientras tanto, los gestores urbanos se hacen cada vez más conscientes de la selectividad espacial y funcional del turismo y se hacen cada vez más prudentes con respeto al equilibrio de los costes y beneficios y especialmente el desequilibrio, en la asignación de los costes locales y visibles con beneficios mayores pero menos notorios. El desarrollo turístico encuentra cada vez una posición mayor en la coalición de ansiosos defensores del medio ambiente, guardianes de la exactitud histórica, antropólogos conscientes del mal uso que se hace de las culturas locales (Smith, 1977), sociólogos preocupados por el "efecto demostración" de los turistas en las sociedades locales, observadores de la explotación política global de los pobres y débiles por los ricos y fuertes en forma de prostitución cultural, (Pfafflin, 1987) e incluso en el neocolonialismo y los economis- 
tas que argumentan que dicho uso parasitario de la cultura es intrínsecamente una estrategia económica insana (Mossetto, 1991).

Sin embargo, el tercer socio, la industria del turismo, parece más desconcertada que ofendida por este enfriamiento del ardor. Responde a las llamadas de la crisis de recursos con la pregunta, ¿qué crisis? Lo que en esencia es un problema de agotamiento de los recursos o un desequilibrio coste/beneficio, se define como un problema de imagen y el negocio como siempre continúa bajo un mantra de declaraciones de misiones sostenibles (Ashworth, 1992; Jansen-Verbeke, 1997; Wheeler, 1992).

Sin embargo, los supuestos de conflicto automático son tan naives como los anteriores supuestos de armonía automática. Asumen entre otras cosas, que los recursos de patrimonio tienen propietarios identificables simples o al menos usos y usuarios prioritarios; que el patrimonio es un suministro fijo de forma que el aumento de la demanda lleva automáticamente a una disminución del recurso; que el uso turístico (y por derivación el turismo y los turistas) es esencialmente diferente y por implicación menos valioso que los usos no turísticos; y que el turismo, como actividad económica, debería evaluarse en base a factores distintos a las actividades económicas locales. Como estos supuestos es probable que se demuestren incorrectos una vez más, esta fase dentro de la relación debería ser también temporal.

\section{Resolución mediante la reconciliación, resignación o separación}

La relación llega por último a una elección de estados finales en los que se vuelve a evaluar el equilibrio entre las ventajas y desventajas de cada participante. La posibilidad continua de ganancias sin una simbiosis rentable mutua se establece en un contexto cada vez más evidente de conflicto potencial. Para los gestores urbanos, tanto el desarrollo de turismo como el refuerzo del patrimonio, son porciones rechazables. Los productores de turismo, pueden no ser capaces de evitar el potencial de creación de productos de las ciudades en general, pero tienen tal amplitud de elección de posibles emplazamientos que cualquiera puede ser rechazado si se opone muy vigorosamente al desarrollo. La separación de uno o más de los socios es, por lo tanto, una posibilidad realista.

Igualmente, esta relación a tres puede ser menos perfecta pero una vez que se tienen en cuenta los socios alternativos puede parecer la mejor combinación posible o posiblemente la única posible. El desarrollo turístico, aunque agrietado, es a menudo una opción de desarrollo de "último recurso". Los gestores del patrimonio siguen necesitando financiar y justificar sus caras actividades y por tanto dan la bienvenida a los turistas aunque desprecian la presencia turística. Ambos descubrirán pronto en cualquier caso, que las políticas locales pueden tener poco efecto en las demandas turísticas o de patrimonio que están regidas por tan amplias consideraciones. Lo que no se puede excluir debe ser necesariamente incluido, sin embargo, con un espíritu de resignación hacia lo inevitable.

Por último no es sorprendente que la idea de desarrollo sostenible se haya valido en gran medida de la industria del turismo, los suministradores de recursos patrimoniales y los gestores de lugares de destino como una solución de bienvenida y un escape del callejón sin salida descrito anteriormente. La reconciliación a través de la sostenibilidad es, no sólo un compromiso político, sino un conjunto de técnicas de gestión aplicables que parecen prometer una vuelta a, si no al primer embeleso, por lo menos, a un estado de cuidados y bienestar y a una armonía rentable mutua sin comprometer los recursos.

\section{Dimensiones de la relación}

Después de haber narrado la historia de la relación a tres como conjunto, se pueden considerar sus dimensiones por separado (ilustración 2). En realidad, no todas las interacciones dentro del triángulo son de la misma importancia para nuestro argumento, pero la comprensión de cualquiera de ellas requiere consideración en relación a las otras. El planteamiento aquí es, en primer lugar, considerar la relación entre los tres elementos por parejas y después intentar combinar los tres. También merece la pena resaltar que los vínculos bilaterales funcionan en dos direcciones que no son necesariamente simétricas.

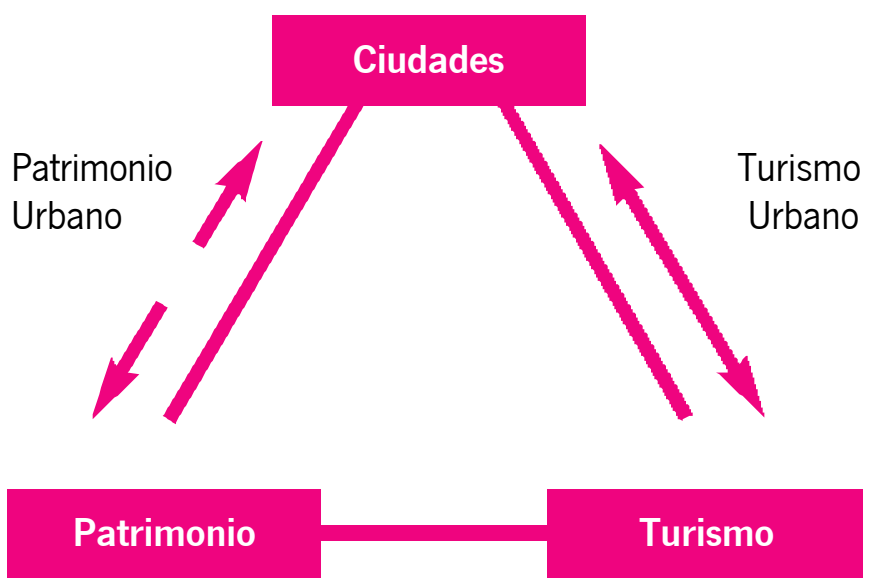

Turismo

Patrimonial

llustración 2: Las relaciones

\section{Ciudades y turismo}

Las relaciones entre las ciudades y el turismo y entre las ciudades y el patrimonio son mucho más amplias que el ámbito de 


\section{$060-061$}

\section{Debate e Investigación}

Historicidad, turismo y política urbana: exploración de la relación entre los tres factores

\section{PH42 - Febrero 2003}

este trabajo. Buena parte del turismo, y de hecho buena parte del patrimonio, se produce fuera de las ciudades, pero la importancia de las mismas para ambos se puede discutir fácilmente pero nos extenderiamos de forma considerable. Solamente mencionaremos algunos aspectos relevantes de dichas interacciones.

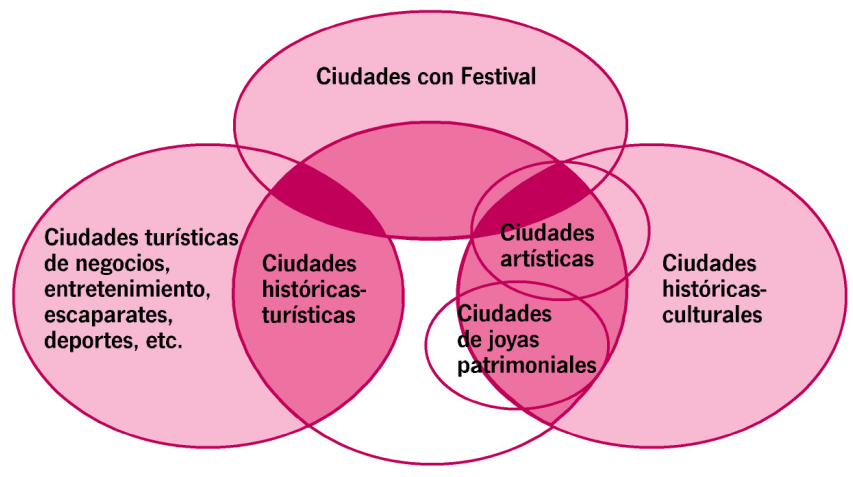

Ilustración 3: Ciudades turísticas

La mayor parte de los turistas provienen de las ciudades y muchos buscan ciudades como destinos para vacaciones por sí mismas o visitan atracciones situadas en las ciudades aunque se alojen fuera de la ciudad. (Page, 1992, 1995; Berg y otros, 1995; Borg y otros, 1996; Law, 1993, 1995). Sin embargo, más importante directamente que nuestros fines es especificar aquellos aspectos de las ciudades que contribuyen a un turismo que no sólo se produzca en las ciudades sino que además sea distintivamente urbano. Son estas características las que relacionan las actividades es- pecificadas del turismo urbano con la forma histórica conservada y son base para buena parte de la discusión de la política.

El lugar central urbano ocupa una posición giratoria dentro de las jerarquía funcionales en el ámbito más amplio regional. Además, y hasta cierto punto de forma contradictoria, las ciudades existen dentro de redes funcionales independientemente de su contexto regional o nacional. Es particularmente marcado en el turismo, en el que la mezcla de cooperación interurbana y competencia puede crear varios tipos de circuitos de turismo nacional o internacional. Por último, el turismo urbano se caracteriza por su variedad en dos sentidos. La variedad de instalaciones que se ofrecen al visitante y la variedad de tipos de vacaciones. Ambas son las principales atracciones de la vacaciones para los turistas. Pero estas instalaciones rara vez se crean exclusivamente para los turistas o son utilizadas exclusivamente por ellos, sino que comparten muchos tipos de uso distintos: en resumen, la ciudad mutifuncional sirve al usuario multimotivado.

Es obvio que la relación entre las ciudades, sus formas y funciones por un lado, y la actividad turística por el otro, ha sido tan estrecha y duradera que la dificultad ha consistido en separarlas más que en encontrar vínculos entre ellas. Las ciudades de turismo patrimonial se describen como un grupo de ciudades de turismo superpuestas (ilustración 3). Las grandes capitales-escaparate, por ejemplo, con sus colecciones imperiales y nacionales, y simbolos y asociaciones, son cuantitativamente las más atractivas para los turistas que buscan ciudades con patrimonio pero de igual forma tienen muchas otras funciones que no están relacionadas ni con el turismo ni con el patrimonio. Por el contrario,

\section{Información}

\section{Fondos europeos para el desarrollo regional y urbano}

Josefina López Galdeano

Oficina de Cooperación IMFE- Ayuntamiento de Granada

\section{Fondos europeos para la regeneración urbana}

La financiación europea más cuantiosa para la regeneración urbana proviene de los Fondos Estructurales ${ }^{1}$, principalmente el Fondo Europeo de Desarrollo Regional (FEDER), que gestiona directamente la Dirección General de Política Regional, y que en este nuevo período (2000-2006) introducen explícitamente la dimensión urbana. Incluyen documentos de programación (Marco de Apoyo Comunitario, Programa Operativo, y Documento Único de Programación), Iniciativas Comunitarias como URBAN II, INTERREG III, e EQUAL, y Acciones Innovadoras. Los
Fondos Estructurales cuentan con un presupuesto de 182.458 millones de euros, de los que 19.733 millones de euros se destina al objetivo 2: "zonas en reestructuración socioeconómica bien sea industrial, rural, urbana o pesquera", para España las figuras son 42.887 euros y 2.553 euros, respectivamente.

El Programa Operativo Local Objetivo 1 (2000-2006) POL. Se trata de una forma de intervención comunitaria pluriregional (en regiones españolas Objetivo 1) cofinanciada por el FEDER, cuyos órganos ejecutores son las administraciones locales, diferenciándose las intervenciones en función del tamaño de los ayuntamientos. Este Programa Operativo fue aprobado por la Comisión de las Comunidades Europeas en 2001 y supone la aplicación de lo dispuesto en el Marco Comunitario de Apoyo de las regiones españolas objetivo 1 para el período 2000-2006. La inversión total prevista de todo el período (2000-2006) asciende a un total de 5.918.142,15 euros, con un global de 4.142.698,30 euros de participación financiera del FEDER. El objetivo estratégico al que se dirige el POL es la búsqueda de un desarrollo territorial equilibrado, desde una perspectiva local y que implica un desarrollo rural y urbano sostenible en el contexto de la estrategia territorial europea. 
las ciudades joyas del patrimonio son indiscutiblemente histórico turísticas pero forman solo una pequeña, y en muchos sentidos, insignificante proporción, de las ciudades histórico turísticas. La designación de "ciudad artística" se le ha otorgado a los lugares que no solamente fueron emplazamientos físicos asociados a los artistas y a sus productos, sino que se han convertido por ellas mismas, incluyendo generalmente sus estructuras físicas, en inseparables con respecto a las obras creativas. Salzburgo es Mozart y Memphis es Elvis. Pero la categoría "artística" y la celebración de festivales puede ser tan amplia que obviamente no todas las ciudades artísticas o de festivales son necesariamente hist órico-turísticas.

Por lo tanto, aunque hay turismo hasta cierto punto en todas las ciudades (no hay ninguna ciudad que no reciba algún visitante) la importancia de su impacto varía no sólo con la magnitud del flujo turístico sino más significativamente aún, con el tipo de ciudad que lo aloja. Existen simplemente muchas formas de turismo urbano y muchos tipos de ciudad turística e incluso añadiendo el adjetivo "patrimonial" tanto al turismo como a la ciudad se consigue reducir poco la variedad.

Por último, se debería recordar que aunque las ciudades son claramente importantes para el turismo, ello no implica automáticamente que el turismo sea importante para las ciudades.

\section{Ciudades y patrimonio}

La relación de historicidad con las ciudades ha de ser explicada, no sólo como un nuevo planteamiento de sabiduría convencional sino como un intento de revelar puntos significativos de influencia de los instrumentos políticos. A menudo, se ha declarado que "el clima urbano es mejor para alimentar la cultura". (Ministerie WVC, 1992) aunque se ha examinado con frecuencia por qué debería ser así, y especialmente cuáles son las consecuencias planificadoras de esta relación. Ello nos lleva a especular sobre tres atributos de lugares básicos que tienen un peso directo sobre los emplazamientos patrimoniales y son el tamaño, la agrupación de espacios y el diseño urbano. Subrayar que las ciudades siempre han jugado un papel primordial en la productividad cultural da la idea de que hay un determinado volumen crítico de interacción humana que se produce en una zona espacialmente restringida y promovida por aspectos de forma urbana que son cruciales para la generación de ideas estéticas. Así podríamos esperar una estrecha correlación entre el tamaño urbano y el turismo patrimonial. Ello es evidente a escala internacional con un puñado de centros metropolitanos escaparate en todo el mundo que incluyen una enorme cuota de monumentos reconocidos mundialmente, asociaciones históricas, museos y similares y que además entretienen a la mayoría del turismo patrimonial mundial. Como gran parte del turismo patrimonial depende de la producción y acontecimientos pasados más que presentes, la lección por tanto, para los centros ambiciosos de turismo patrimonial, es no sólo lograr un crecimiento urbano sino convertirse en un escaparate nacional, o mejor imperial, artístico y ser anfitrión de acontecimientos y personalidades históricas a nivel mundial.

Las otras cualidades urbanas de diseño y forma morfológicos son caminos menos ciertos hacia el éxito pero mucho más fácil-
La Iniciativa Comunitaria URBAN II $^{2}$ pretende abordar y resolver los problemas de zonas urbanas con un alto grado de degradación física, económica y social, incluyendo "zonas centrales de gran valor cultural y patrimonial que han sido abandonadas y dejadas en declive" ${ }^{\prime \prime}$ y apoya la formulación y puesta en práctica de estrategias particularmente innovadoras de regeneración económica y social sostenible en un número limitado de zonas urbanas de Eur ropa. Durante el período de programación 1994-1999, URBAN subvencionó programas en un total de 118 zonas urbanas. En el contexto de la iniciativa URBAN II La financiación se concentra en la regeneración física y ambiental, integración social, formación, espíritu empresarial y empleo, y ofrece más de 728 millones de euros con cargo al FEDER, 110,3 euros para España. En el período actual se han seleccionado un total de 70 áreas europeas, de ellas 10 áreas españolas y 2 en Andalucia, Granada y Jaén.

La Iniciativa Comunitaria INTERREG III. El objetivo de la nueva fase de Interreg es reforzar la cohesión económica y social en Europa fomentando la cooperación transfronteriza, transnacional e interregional y el desarrollo equilibrado de su territorio, prestándose particular atención a las fronteras exteriores de la Comuni- dad, sobre todo en la perspectiva de la ampliación. Durante el período de programación 1994-1999, la iniciativa Interreg II continuó la actividad desarrollada por Interreg y REGEN durante el período anterior y amplió su ámbito de aplicación. Esta nueva fase de la iniciativa se concretará en tres capitulos y tiene una dotación global de 4875 euros, 900 euros para España:

Capítulo A: fomentar el desarrollo regional integrado entre las regiones fronterizas. A este capitulo se dedica el grueso de los recursos financieros, un 67\%. En Andalucia las zonas subvencionables son Huelva, Cádiz, y Málaga.

Capítulo B: contribuir a la integración territorial y lograr un desarrollo duradero, armonioso y equilibrado en la Comunidad y una mayor integración territorial con los paises candidatos y otros paises vecinos. Los espacios subvencionables que afectan Andalucía son Mediterráneo Occidental (MEDOC), Espacio atlántico (Huelva), y Europa Sudoccidental (SUDOE), y constituyen el 26\% del presupuesto global de la iniciativa.

Capitulo C: mejorar las políticas y técnicas de desarrollo regional y cohesión mediante la cooperación transnacional e interregional. Este capítulo es, con mucho, el de menor dotación económica, 6\%. 


\section{$062-063$}

\section{Debate e Investigación}

Historicidad, turismo y política urbana: exploración de la relación entre los tres factores

\section{PH42 - Febrero 2003}

mente influenciables por políticas de planificación local. Si la productividad cultural es producto de la interacción social, ello se ve promovido por determinados diseños urbanos que pueden ser diseñados por las políticas de planificación. La llamada "función forum" de las ciudades se puede ver promovida por la creación de foros. Los planificadores locales han respondido y además han promovido, los cambios en el comportamiento de espacio social en las ciudades con el diseño de terrazas al aire libre, plazas y arcadas (Oosterman, 1993; Burgers, 1995). El argumento determinista medioambiental es que la creación de una forma urbana similar a la Florencia o Venecia del s. XV puede tener unas consecuencias artística similares o al menos puede crear una ilusión, en la medida que lo permita el clima del norte de Europa, de dicho entorno (Ennen, 1997). Dicha ingeniería cultural, puede parecer una estratagema pero las ciudades que se esfuerzan en proyectarse a sí mismas como centros patrimoniales dependen en un grado importante de la estructura y calidad de sus formas físicas, especialmente en aquellos distritos en los que se han promovido como emplazamientos patrimoniales (Tiesdell y otros, 1996).

Los gobiernos locales, en la mayoría de los países, tienen facultades considerables sobre el uso de la tierra, y muchas ciudades han puesto en marcha políticas que han dado como resultado, ya sea intencionadamente o no, un grupo compacto espaciado de emplazamientos patrimoniales. La asociación funcional, el reagrupaje espacial y la creación de sinergías positivas efectivas son especialmente importantes en el turismo patrimonial (Dietvorst, 1995). Como consecuencia, la gestión local tiene los medios, mediante el uso de instrumentos legales existentes hace tiempo, para intervenir de forma eficaz (Ashworth y Tunbridge, 1990; 2000; Ashworth, 1992; Larkham, 1996). La planificación del patrimonio, incluyendo la planificación para su uso turístico, es así un aspecto integral de una planificación urbana local mucho más amplia.

\section{El Patrimonio y el turismo}

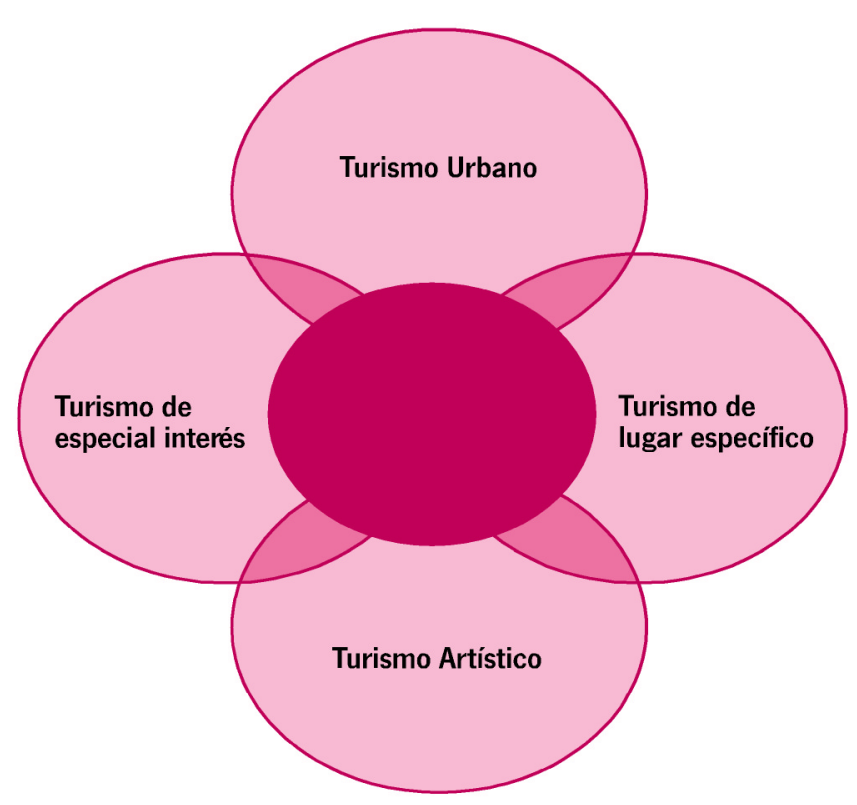

Ilustración 4: Tipos de turismo
>> La Iniciativa Comunitaria EQUAL ${ }^{4}$ viene a reforzar los fondos e iniciativas anteriores con un presupuesto de 2.847 millones de euros, 485 millones de euros para Andalucía. A partir de las lecciones aprendidas con los programas Empleo y ADAPT, EQUAL servirá de campo de pruebas para desarrollar y difundir nuevas maneras de aplicar las políticas de empleo, lo que constituye en elemento determinante para una regeneración urbana integral. En Andalucia se han aprobado 21 proyectos con la participación de la CEDT de la Junta de Andalucía.

Las Acciones Innovadoras del FEDER $^{5}$ constituyen laboratorios de ideas en beneficio de las regiones desfavorecidas, y aportan a los agentes regionales "un laboratorio" para las dificultadas que plantea la nueva economía. Los tres temas estratégicos de este periodo son: economía regional basada en el conocimiento y la innovación tecnológica; e-Europa: la sociedad de la información al servicio del desarrollo regional; e identidad regional y desarrollo sostenible. Están dotadas de un presupuesto de aproximadamente 1.000 millones de euros, es decir, el 0,5\% de los créditos de los Fondos Estructurales.

\section{Programas europeos para la regeneración urbana}

El Marco comunitario de cooperación para el Desarrollo Sostenible en el Medio Urbano (2001-2004) proporcionará apoyo financiero y técnico a redes de autoridades locales organizadas en al menos cuatro Estados miembros, con el fin de fomentar la concepción, el intercambio y la aplicación de buenas prácticas en los ámbitos de aplicación local de la legislación comunitaria en el sector del medio ambiente, desarrollo urbano sostenible, y Programa 21 Local. La dotación financiera para el período 20012004 ascenderá a 14 millones de euros.

El V Programa Marco de Investigación (1998-2002), Acción Clave "Ciudades del Mañana y Patrimonio Cultural", de la Comisión Europea para investigación y desarrollo tecnológico. El presupuesto de esta acción es de 170 millones de euros y tiene como objetivo principal la integración de cuatro corrientes: la sostenibilidad urbana, la preservación y mejora del patrimonio, la construcción sostenible y el transporte urbano. El VI Programa Marco de Investigación (2002-2006) ${ }^{6}$ desarrollará políticas urbanas en los programas de"Desarrollo sostenible, Cambio Global y Ecosis- 


\section{Gestión de la historicidad para los turistas}

La única tendencia social y económica de los últimos treinta años que justifica una preocupación por el turismo patrimonial en ésta conferencia es simplemente que los turistas se han interesado de forma demostrable cada vez más en consumir el patrimonio. Silberberg (1995) ha ilustrado este punto examinando las preferencias turísticas del mercado norteamericano y se ha dado cuenta de que se ha producido una deriva discernible desde los 80, con lo que él define como escapismo, tipificado por los gastos de lujo, hasta los 90 con un enriquecimiento que se refleja en el consumo de experiencias históricas, culturales e incluso espirituales. La conclusión importante es que dicha deriva, aunque esté definida, se nota tanto en la sociedad en su conjunto, como en la actividad turistica especifica.

El turismo patrimonial se puede definir como la zona intermedia entre una serie de distintos turismos (Ilustración 4) en particular, procede de dos grandes categorias generales de turismo que se han etiquetado como de "interés especial" y "lugar específico" (Ashworth, 1995). El turismo de interés especial intenta durante las vacaciones hallar intereses que probablemente existen fuera de esas vacaciones. El interés de la gente que está de vacaciones en las reliquias de asociaciones del pasado es sólo la ampliación del mismo interés que expresan habitualmente cuando no están de vacaciones: el turista de patrimonio por lo tanto, no muestra un comportamiento excesivamente extraño en términos de turismo. De forma similar, la existencia de atractivos históricos es habitualmente una respuesta menor a la demanda de turismo, que las necesidades sociales mucho más amplias, y por lo tanto, no se puede explicar dentro del propio turismo. El turis- mo de lugares específicos se da cuando el atractivo del turismo se concentra en el lugar en sí mismo que puede estar compuesto por muchos atributos culturales definidos. Aunque todo turismo se produce en algún lugar y todos los lugares son únicos, ésta forma de turismo utiliza esta cualidad única más que las características genéricas de un lugar, como el producto turístico. El turismo patrimonial se compone tanto de un interés especial como de un lugar específico, pero sólo cuenta con una parte de ambas categorías. Existen otras dos categorías de turismo importante y son el turismo urbano y el turismo cultural. La primera abarca claramente al turismo patrimonial aunque es más amplio. La segunda incluye una amplia gama de tipos posibles de atractivo cultural, tal y como pueden observarse en los resultados de un estudio de alcance europeo de respuestas a la pregunta "¿qué considera como fuentes culturales importantes?". En el mismo estudio, Jansen-Verbeke (1997) distingue entre el turismo que está culturalmente "motivado" (es decir es el objetivo del viaje), "inspirado" (es decir, se puede incluir en un paquete turístico mayor), y el "atraído" (es decir se produce incidentalmente con los "excursionistas en vacaciones"). No sabemos si esta distinción es útil en la práctica o no, y por ello se subraya la ambigüedad esencial de la idea de turismo cultural. Además, la superposición entre el turismo patrimonial y el turismo cultural es tan estrecha que los términos se utilizan a menudo de forma sinónima (Prentice, 1996). De forma más precisa, el turismo artístico se puede definir como consumo turistico de los productos artísticos e interpretaciones de una cultura (aunque la creatividad originaria presentada no tiene que ser necesariamente autóctona del lugar de la representación). Se puede discutir que todo el arte es patrimonio real o potencial y algún temas" (2.120 millones de euros) y "Ciudadanos y Gobierno Urbano en la Sociedad de la Información" (225 millones de euros).

Cultura 2000 (2000-2004) $)^{7}$ desarrolla medidas en el campo de la cultura y su presupuesto es de 167 millones de euros. Este programa de la UE pretende contribuir a la promoción de un área cultural común a los europeos, apoyar la cooperación entre artistas, operadores culturales e instituciones culturales de sus estados miembros (artes visuales y plásticas, literatura, patrimonio, historia cultural, etc.).

Otro programa relacionado con lo urbano es LIFE, que sustituye y deroga a las acciones comunitarias medio ambientales anteriores: ACNAT (acción para la conservación de la naturaleza), MEDSPA (protección de medio ambiente en las regiones mediterráneas) y NORDSPA (protección de las zonas costeras del norte). El reglamento 1655/2000 inaugura la tercera etapa de Life durante el período 2000-2004. LIFE consta de tres ámbitos temáticos: LIFE-NATURALEZA, LIFE-MEDIO AMBIENTE (gestión del agua y los residuos, reducción del impacto medioambiental de las actividades económicas, ...) y LIFE-TERCEROS PAÍSES.

\section{Regeneración urbana y cooperación}

La Comisión Europea gestiona una serie de instrumentos financieros que permiten el desarrollo de programas de cooperación entre estados miembros de la Unión Europea con otras áreas geográficas. Los más relevantes en relación con la regeneración urbana son:

Programa MEDA ${ }^{8}$. Hasta 1991 se firmaron tres series de protocolos de asociación euro mediterránea: 1er. Protocolo 1978-81, $2^{\text {a }}$ Protocolo 1982-86, 3er. Protocolo 1987-91 con un presupuesto global de 1.714 millones de euros. Los cuartos Protocolos entraron en vigor en noviembre de 1991 para un período de cinco años (1992-1996). El programa MEDA sustituyó a los protocolos cuando finalizaron su plazo de aplicación (31.12.96) y es el resultado de la Conferencia Euro mediterránea celebrada en Barcelona el 28 de noviembre de 1995. Durante el periodo 1996-1999 se ejecutó el primer plazo del programa. Mediante el Reglamento 2698 /2000 se aplica el segundo tramo correspondiente al período 2000-2006, con un presupuesto 5350 millones de euros. El objetivo del programa es contribuir a la realización de iniciativas de in- 〉» 


\section{$064-065$ \\ Debate \\ e Investigación}

Historicidad, turismo y

política urbana: exploración

de la relación entre los tres factores

\section{PH42 - Febrero 2003}

patrimonio, pero no todo, es también arte, pero la superposición no es completa. Buena parte del arte y la arquitectura modernos no encajan bien en los paquetes de turismo patrimonial, aunque con el tiempo, puede que lo hagan y que así al menos se pueda considerar patrimonio potencial. Algunos edificios se pueden conservar por su significado o asociaciones históricas más que por la calidad estética de su apariencia. Sin embargo, la mayor parte de los edificios conservados se valoran por su calidad artística así como por su historicidad. Por lo que respecta al turista, el contenido de museos históricos, galerías de arte no contemporáneas e incluso la mayoria de las representaciones artísticas, es probable que se incorporen al patrimonio experimentado por los visitantes junto a los edificios y emplazamientos históricos, muchos de los cuales albergan además colecciones artísticas.

El patrimonio se puede diluir dentro de un "turismo cultural" más ampliamente definido basado en algo más que en la curiosidad sobre las distintas formas de vida. Sus destinos se marcan como exóticos y éste exotismo incluye aspectos de folklore que pueden ser tanto arte (o por lo menos "artesanía") como la relación con el pasado, pero que además tiene algo diferente. Por ejemplo, el crecimiento de un turismo basado en el "Ryo Kam", (posadas tradicionales), el "Onsen" (manantiales calientes) y el "Tatami" (alfombrillas para dormir) ha sido descrito por Graburn (1995) como una combinación de "nostalgia y neotradicionalismo" destinado simplemente a reforzar "la idea de lo Japonés" tanto para los mercados domésticos como para los extranjeros. Incluso se puede desarrollar dicho turismo cuando las diferencias culturales entre el anfitrión y el invitado son fundamentalmente distintas.
Por ejemplo, enclaves como las Islas de St. Pierre y Miquelon deben su éxito turístico esencialmente a su situación frente a la Costa de Terranova en la que se promocionan como un "pequeño trozo de Francia" en Norte América. Dicho turismo cultural está menos asociado con el arte o la historia y más con la presencia de gendarmes y equipos franceses pero, sin embargo, conlleva, aunque vagamente definida, una experiencia de patrimonio.

El turismo patrimonial se puede localizar por tanto en el punto convergente de la superposición de esta tres categorias de turismo.

Los turistas, por lo tanto, hacen uso de varios tipos de patrimonio de varias formas. Los recursos utilizados en la producción de productos turísticos de patrimonio tienen cuatro características especialmente importantes, a saber, variedad, ubicuidad, demanda compartida y marginalidad.

La primera y más obvia es la variedad: Ios turistas consumen una enorme heterogeneidad de productos y servicios de patrimonio, estén pensados para ellos o no. Un inventario inevitablemente incompleto de dichos recursos incluiría no sólo las instalaciones más protegidas, como los museos, exposiciones, emplazamientos o monumentos principales sino también muchas más instalaciones comunes que, a pesar de ello, son vistas por los turistas como parte importante del patrimonio. El "turismo de lugar específico" utiliza los Bistros en París, el Gran Bazar de Estambul, el Mercado Flotante de Bangkok, los canales de Ámsterdam y similares como un patrimonio generalizado que identifica y caracteriza la experiencia de los lugares específicos. Esta variedad tiene como resultado productos altamente diversificados que satisfacen
»> terés común en los tres aspectos de la colaboración euro mediterránea: fortalecimiento del área de la estabilidad política y de la democracia, creación de una zona de libre comercio euro mediterránea y desarrollo de la cooperación económica y social y consideración de la dimensión humana y cultural.

ASIA-URBS (2001-2005, $2^{\text {a }}$ fase) ${ }^{9}$. El programa constituye un marco de cooperación descentralizada entre Europa y Asia. La parte principal del programa se centra en la cooperación directa entre los gobiernos locales de Europa y Asia en estrecha colaboración. Los temas que aborda el programa son planificación urbana, incluyendo el desarrollo institucional y las políticas y técnicas de planificación; desarrollo socioeconómico urbano, incluyendo la participación de las mujeres en las ciudades, disminución de la pobreza urbana; medio ambiente urbano, conservación y rehabilitación; gestión del agua y de los residuos; e infraestructura social urbana. Cuenta con un presupuesto de 26.2 millones de euros.

ALFA (2000-2005, $2^{\text {a }}$ fase $)^{10}$. El programa ALFA se dirige a las instituciones de enseñanza superior de 18 países de América Latina y de los Estados miembros de la Unión Europea, con un pre- supuesto de 42 millones de euros. Esta dividido en acciones para la Cooperación para la gestión institucional, y Cooperación para la formación científica y tecnológica. ALFA concede prioridad a los proyectos académicos referidos a las ciencias económicas y sociales en general (gestión de empresas, administración pública, economía y derecho económico, estudios medioambientales, integración regional, desarrollo rural, planificación urbana y regional y política social y educativa), las ingenierías, la medicina y otras ciencias de la salud.

URB-AL (2001-2006, $2^{\text {a }}$ fase) La Ciudad en Acción $^{11}$ es un programa de cooperación descentralizada, adoptado por la Comisión Europea en diciembre de 1995 que va dirigido a las ciudades, aglomeraciones y regiones de la Unión Europea y de América Latina, del que se han beneficiado hasta la actualidad 700 ciudades (8 redes temáticas y 49 proyectos) y que en su segunda fase tiene una duración de 5 años y un presupuesto de 50 millones de euros. Las nuevas redes son: financiación local y presupuesto participativo, lucha contra la pobreza urbana, vivienda en la ciudad, promoción de las mujeres en las instancias de decisión locales, ciudad y sociedad de la información, y seguridad 
a unos mercados "nichos" cada vez más segmentados.

En segundo lugar, el patrimonio es un recurso ubicuo. Aunque algunos lugares se pueden asociar con un acontecimiento, personalidad o estructura histórico particularmente reconocido, todos los lugares tienen un pasado esté registrado históricamente o no, y todos los pueblos tienen su patrimonio esté interpretado como distintivo o no. Un recurso de ubicuidad dota a cualquier lugar de la posibilidad de obtener productos de patrimonio en un mercado tur rístico: y esta posibilidad universal intensifica la competencia dentro de dicho mercado. Conforme aumenta la oportunidad de acceso, también disminuye la posibilidad de éxito de cualquier lugar.

En tercer lugar, la demanda de productos y servicios patrimoniales la comparten los turistas y una amplia variedad de usuarios de otro tipo. En particular, tienen importantes tareas de socialización local, identificación y legitimación política (Graham y otros 2000). Ello conlleva muchas implicaciones prácticas para la gestión de recursos para los que fueron creados y sirven para otros muchos usos.

Por último, el turismo generalmente hace uso de los recursos que no se pensaron originariamente para el mercado turístico y que actualmente son propiedad y están gestionados por aquellos que son inconscientemente indiferentes e incluso hostiles hacia dicho uso (Borg y otros, 1996). Las implicaciones prácticas en la industria del turismo, de turistas que hacen un uso extramarginal y de productos de marketing hechos de recursos sobre los que no se tiene control, nos lleva a muchas dificultades detalladas que van desde la superocupación, a los inconvenientes de las obras de apertura, a las interpretaciones irrelevantes o a las ins- talaciones de apoyo inadecuadas.

\section{Cómo gestionar el turismo para la historicidad}

No sólo hay que entender la naturaleza peculiar del recurso patrimonial sino que también hay que entender la naturaleza y la motivación del turismo patrimonial y, por lo tanto, el modo en el que los turistas lo utilizan.

Es difícil separar la explicación del interés de los turistas en el patrimonio, de otros dos contextos. Los viajes en general han aumentado continuamente y los viajes a ciudades se ven motivados por una amplia variedad de funciones y atractivos urbanos de los que el patrimonio es sólo una parte. Florencia aloja 4.2 millones de visitantes-noches y Salzsburgo 1.9 millones pero ciudades con recursos de patrimonio mucho menores, como Hamburgo (4.1 miIlones de visitantes-noches), Lyon (2.9 millones) o Zurich (2.0 millones), también se han beneficiado del crecimiento general de los viajes (Berg y otros, 1995; Borg y otros, 1996). En segundo lugar, los cambios fundamentales de la naturaleza de la sociedad y por tanto, en el comportamiento del consumidor, han reforzado la adaptación de los productos culturales a, si no un consumo masivo, al menos un consumo por mercado mucho más amplio y variado que las pequeñas élites culturales de la anterior generación. Los turistas que consumen patrimonio (en forma de arquitectura histórica, colecciones de obras de arte, tradiciones folklóricas y souvernirs artesanales) pueden estar simplemente continuando con sus actividades diarias; y su comportamiento de consumo, a menudo, no se distingue del de los residentes. Cuando este es el caso, el turismo patrimonial tiene un significado menos distintivo de lo que se podría haber imaginado, originado en parte, sin duda, por la dificultad de aislarlo estadísticamente. ciudadana. Las actividades desarrolladas en el marco de URB-AL son: Encuentros Bienales, Redes Temáticas de Interés Mutuo y Proyectos Comunes.

\section{Otros instrumentos de financiación}

El Banco Europeo de Inversiones $(B E I)^{12}$ financia planes de regeneración urbana y proyectos urbanos representativos, así como sistemas de transporte urbano y en calidad del entorno, incluida la vivienda social. El Programa de Acción Especial de Ámsterdam del BEI también proporciona recursos para inversiones a largo plazo en educación, formación y sanidad.

Otros organismos que estudian el tema urbano en el que se encuadran los centros históricos son las Naciones Unidas mediante el documento Habitat II y la Agenda 21, la UNESCO mediante sus organizaciones ICOMOS e ICCROM, el Banco Mundial a través de su "Visión Estratégica de temas urbanos y de gobiernos locales: implicaciones para el Banco", etc.

\footnotetext{
${ }^{1}$ http://europa.eu.int/comm/regional_policy/themes/urban_es.htm

${ }^{2}$ http://europa.eu.int/comm/regional_policy/urban2/intro_es.htm

${ }^{3}$ Fact sheet 15.11.1998 En "URBAN: Restoring hope in deprived neighbour hoods". EU. Regional Policy and Cohesion

${ }^{4}$ http://www.redicand.cedt.junta-andalucia.es/equal/_proyectosaprobados.asp

${ }^{5}$ http://europa.eu.int/comm/regional_policy/themes/infotech_es.htm

${ }^{6}$ http://europa.eu.int/comm/research/fp6/index_en.html

${ }^{7}$ http://europa.eu.int/comm/culture/eac/c2000condition_en.html http://www.mcu.es/cooperacion/pcc/p_pcc.html

${ }^{8}$ http://europa.eu.int/comm/external_relations/euromed/

9 http://europa.eu.int/comm/europeaid/projects/asia-urbs/index_en.htm

${ }^{10} \mathrm{http}$ ///europa.eu.int/comm/europeaid/projects/alfa/index_es.htm

${ }^{11}$ http://europa.eu.int/comm/europeaid/projects/urbal/index_es.cfm

12 http://www.bie.org
} 


\section{$066-067$ \\ Debate \\ e Investigación}

Historicidad, turismo y

política urbana: exploración

de la relación entre los tres factores

PH42 - Febrero 2003

Hay dos explicaciones principales para el crecimiento del interés de los turistas por el patrimonio y cada una de ellas es parte de una explicación más general del crecimiento del interés por la cultura en su conjunto. Existe una tesis de aburguesamiento en la que el consumo de cultura es parte del estilo de vida de un estrato social distintivo identificable en términos de edad, renta, estatus social y educación. El patrimonio se ve como el objetivo de una élite minoritaria que da forma al gusto social equipada con las habilidades y experiencia exigidas por Urry's 1994, Cosmopolitan. Muchos estudios de turistas en emplazamientos patrimoniales identifican el dominio de dichas características estructurales (Hughes y Gratton, 1992; Prentice, 1993). Los cambios en la distribución de los ingresos disponibles, y en la sociedad, han ampliado sucesivamente este mercado (Masser y otros. 1994).

Dos estadísticas distintas respaldan esta teoría. En primer lugar, ha habido un crecimiento notable en las visitas al patrimonio y en las interpretaciones culturales y la venta de artículos culturales en los últimos 30 años en las culturas occidentales (Wynne, 1992; Evans, 2000). En segundo lugar, es fácil presentar un perfil del turista de patrimonio medio (Ashworth y Tunbridge, 1990; Prentice, 1993) 40-60 años, ingresos y educación por encima de la media, sin carga de niños y relativamente experimentando en ese tipo de vacaciones. Sin embargo, dichas generalizaciones esconden que la gran variedad de submercados que subyacen en el patrimonio habitualmente no son muy útiles para ayudar a la gestión.

Una teoría alternativa, interpretada más desde el lado de la oferta que del de la demanda, podría ser llamada la tesis de democratización, en la que aquellos que se preocupan por la creación y conservación del patrimonio han ampliado la definición de sus responsabilidades y su línea de productos sucesivamente, buscando nuevos mercados y usando nuevas técnicas de promoción y presentación. Entre los motivos para esta tendencia se incluyen las ideas de responsabilidad social y supervivencia económica en un contexto de reducción de la generosidad pública. En la "nueva museología" (Vergo 1989; Merriman, 1991) la promoción, presentación e interpretación son la base más que los propios objetos de valor. Ciertamente, el turismo patrimonial ha dejado de estar confinado a las artes superiores de los clásicos establecidos, pero ofrece una amplia gama de productos de patrimonio y una ampliación de la definición de patrimonio en la que se incluye el patrimonio "diario" de la gente corriente. Una de las consecuencias es que, el mayor porcentaje del mercado de turismo se familiariza con los productos de patrimonio durante las vacaciones y, por tanto, se puede ver atraido por ellos.

Al movernos de las respuestas a la pregunta "¿por qué?" a las de la pregunta "¿cómo?" se puede afirmar en términos generales que los turistas utilizan el patrimonio de forma selectiva, rápida y caprichosa.

El uso turístico del patrimonio es muy selectivo y esta selección es completamente distinta de la realizada por otros usuarios. La industria del turismo hace un uso intensivo de un extremadamente limitado número de edificios y emplazamientos en una pequeña porción de lugares históricos. Los monumentos mayores, más excepcionales y espectaculares y los acontecimientos más dramáticos se prefieren antes que los monumentos pequeños, domésticos y más comunes quedando éstos últimos, así como la historia que representan, sin visitar por los turistas (Ashworth, 1995). La selec-

\section{Información}

\section{¿Qué es una Agenda 21 Local?}

\section{Equipo de trabajo de la Agenda 21 Local de Granada}

En junio de 1992 se celebró en Río de Janeiro la Conferencia sobre Medio Ambiente y Desarrollo donde se llamó la atención sobre la necesidad de fomentar el desarrollo sostenible a escala mundial. De esta conferencia surgieron la denominada Carta de la Tierra y el Programa 21 o Agenda 21, a los cuales se adhirieron 173 gobiernos, entre ellos todos los Estados miembros de la Unión Europea. La Agenda 21 establece iniciativas específicas, donde se pide a los gobiernos que elaboren estrategias nacionales de desarrollo sostenible. No se trata de un convenio que obli- gue legalmente a los signatarios, pero la Agenda 21, sin ser vinculante ha ejercido un gran influjo a nivel mundial.

Una gran parte de la Agenda 21 se dirige hacia el medio ambiente urbano, apostándose por el fomento de la economía urbana sostenible, la ordenación del territorio así como la integración de la planificación del transporte y la planificación espacial. Una preocupación central de la Agenda 21 está en el aumento de la capacidad institucional para conseguir el desarrollo sostenible. Para ello se incluyen procedimientos y medios que los gobiernos nacionales y comunidades locales tienen para desarrollar todo aquello que les permita gestionar el medio ambiente y los recursos naturales.

La plasmación en Europa de la Conferencia de Río ha venido de la mano de las iniciativas locales, que han liderado el espíritu de la Agenda 21. En 1994 se celebra en Aalborg (Dinamarca) la Primera Conferencia Europea de Ciudades y Poblaciones Sostenibles, en la cual 80 autoridades locales europeas firman la Carta 
ción del turismo se puede explicar mediante el conocimiento, las expectativas y las limitaciones tiempo/espacio del turista. Por lo que respecta al turismo, la respuesta a la pregunta "¿qué historia y qué patrimonio va a ser objeto de consumo?" será siempre "el patrimonio reconocido como relevante por el visitante". El visitante tiene un conocimiento distinto y más limitado del lugar que va a ser visitado que el residente. Un patrimonio local complejo y rico se puede ver reducido a unas simples características reconocibles y comerciables - Nottingham es Robin Hood y Heidelberg el Príncipe Estudiante. Los visitantes hacen una evaluación diferente de los objetos históricos, enfatizando aquellos aspectos de la historia local que se pueden relacionar con la experiencia del visitante o satisfacer los requisitos del mismo mientras ignoran aquellos aspectos que no se puedan relacionar. Todo el patrimonio es una selección de muchos pasados locales posibles y el patrimonio del turista y el del residente pueden ser lo suficientemente distintos para iniciar conflictos en la selección, interpretación y uso. El patrimonio presentado a los ciudadanos será distinto en énfasis al presentado a los visitantes, irrelevante con respecto al mismo o en el peor de los casos entrará en conflicto con él. Es especialmente el caso en el que los origenes culturales de los visitantes y residentes son muy distintos y en el que la política de conservación es una actividad local descentralizada que persigue objetivos ampliamente locales.

La segunda generalización más importante sobre la naturaleza del turismo patrimonial con respecto a su gestión es que los productos de patrimonio se consumen muy rápidamente. A pesar del crecimiento en interés por el patrimonio y de la ampliación de la variedad de los productos del patrimonio, cualquier producto de patrimonio específico se consume rápidamente, especialmente si lo comparamos con el tiempo que se tardó en crear. La du-

de las Ciudades Europeas hacia la Sostenibilidad (Carta de Aalborg), de donde nació la Campaña Europea de Ciudades Y Poblaciones Sostenibles destinada a animar y prestar apoyo a las ciudades y pueblos para que trabajen en pro de la sostenibilidad. Cualquier autoridad local o conjunto de ellas puede adscribirse a la Campaña aprobando y firmando la Carta, lo que compromete a la autoridad local a participar en un proceso de Agenda 21 Local, creando y llevando a la práctica un plan de acción para la sostenibilidad, así como organizando la participación ciudadana en torno a un Foro Ambiental que ayuda a priorizar problemas y proponer planes ambientales. Con posterioridad, en 1996, se celebra la Segunda Conferencia, elaborándose la Carta de Lisboa, denominada El Plan de Acción de Lisboa: De la Carta a la Acción. Por último, en febrero del año 2000, tuvo lugar la Declaración de Hannover de los líderes municipales en el umbral del siglo XXI. A la fecha de esta Conferencia, habian suscrito la Carta 650 autoridades locales y regionales de 32 países europeos que representan a 130 millones de ciudadanos. ración media de estancia de un visitante incluso en las ciudades con patrimonios más famosos, cuyos edificios han evolucionado a lo largo de un milenio, es sólo de 2 a 3 dias (por ejemplo Salzburgo, 2.0; Venecia, 2.3): las principales ciudades del mundo obtienen unas cifras un poco mejores (París, 2.2; Berlín 2.5; Londres 5.6) (Borg y otros, 1996). Los centros históricos o culturales más pequeños pueden medir la estancia de visitantes solo en horas: incluso los visitantes motivados en primer lugar por el arte, permanecerán sólo unas horas en activa participación para lograr su fin. Ello tiene una serie de consecuencias. Sólo unos pocos productos de patrimonios individuales, por otra parte únicos, pueden sostener por sí mismo un turismo local. Las implicaciones son que se requiere una gama de productos y elementos de apoyo que subraye la importancia crítica de comprender la forma en la que varios elementos están relacionados a través del comportamiento en tiempo y espacio del visitante (Dietvorst, 1994, 1995) y en segundo lugar, que los lugares de patrimonio turístico existen dentro de redes de otros tipos de lugares, ya sea ofreciendo unos atractivos similares o complementarios.

Por último, en cualquier actividad discrecional, la moda juega un papel importante. El turista de patrimonio, con cada vez mayor experiencia y sentido de la aventura, ejercita una elección cada vez más caprichosa, arbitraria e inconstante de un conjunto de atracciones que se expande rápidamente. Los clásicos establecidos del canon cultural occidental ya sea en música, teatro, bellas artes, arquitectura, diseño urbano o personalidades y asociaciones históricas se han visto ampliados por una gama cada vez mayor de experiencias de patrimonio. La reacción de los productores a esas demandas cambiantes de los consumidores con gustos cada vez más eclécticos en un mercado altamente competitivo es rápida, flexible y responde a la diversificación de la línea de productos (Boniface y Fowler, 1993; Prentice, 1993; Ashworth, 1995; Herbert, 1995; Robinson y otros, 1997).

\section{La gestión del turismo patrimonial para el desarrollo local}

Las tres consideraciones principales de este trabajo, los recursos patrimoniales, el uso del turismo y las estrategias de desarrollo de la gestión de lugares se estudiarán conjuntamente.

El patrimonio, el turismo y la gestión de las economías locales Los impactos económicos del turismo en general (Sinclair y Stabler, 1997) y el de las ciudades en particular (Page, 1992; 1995; Van der Borg, 1990; Van Den Berg y otros., 1995; Borg y otros., 1996; o Law, 1993, 1995) conforman un tema muy bien investigado. La economía de patrimonio, sin embargo, está muy poco estudiada (Lichfield, 1988; Stabler 1996; Graham y otros, 2000). Comparado con otras formas de turismo, el turismo patrimonial tiene unos gastos diarios relativamente altos como resultado de estar basado predominantemente en las estancias en los hoteles $y$, por tanto, este beneficio económico directo tenderá a incre- 


\section{$068-069$ \\ Debate \\ e Investigación}

Historicidad, turismo y

política urbana: exploración

de la relación entre los tres

factores

\section{PH42 - Febrero 2003}

mentar los beneficios de alojamiento y otros servicios más que mejorar las instalaciones de patrimonio en sí mismas que frecuentemente tienen tarifas bajas o inexistentes. Por lo tanto, los dos factores que determinan el beneficio económico son el número de noches de estancia y los vínculos económicos entre las instalaciones de patrimonio y los servicios secundarios. Los lugares de excursiones de día por ejemplo, ganan poco económicamente, independientemente del volumen de turistas que las visiten durante unas horas. Los costes económicos, así como los beneficios, tienden a estar limitados espacial y funcionalmente en sus impactos como resultado, en parte, del agrupamiento espacial argumentado anteriormente. Depende de la circunstancias locales, si es ventajoso en su concentración defensiva de impactos negativos en áreas especificas o si es una desventaja por la concentración de costes, así como por el fracaso al intentar repartir los beneficios de la demanda turistica en un área mayor.

Al igual que este papel directo de actividad comercial por si misma, el turismo patrimonial puede jugar una serie de papeles menos directos pero igualmente importantes dentro de la economía local. El hecho de que el turismo es solamente uno de los usos de las instalaciones de patrimonio puede reforzar su significación económica secundaria. Para una representación, museo o monumento que ya existe y continuará existiendo con otros objetivos, el turista es una ganancia neta al menos hasta alcanzar una determinada capacidad física. También se le puede dar la vuelta a este argumento. Las instalaciones de patrimonio creadas para los turistas o sustentadas económicamente por los mismos, pueden ser utilizada además por los residentes.

El tercer papel es más difuso y difícil de cuantificar. Las instalacio- nes de patrimonio que no son económicamente viables por sí mismas se incluyen a menudo en proyectos multifuncionales (Snedcof, 1985; Whitt, 1987; Bianchini, 1993; Lim, 1993) a causa de los factores externos positivos a los que contribuyen a desarrollar y a causa de los distritos. Se pueden resumir en "animación", que incluye llevar a la gente a las calles, especialmente cuando otras instalaciones están cerradas y crear una vida que en sí misma es una atracción (Burgers, 1995) y en 'sello', que es un aura de respetabilidad, continuidad y mecenazgo de lugar artístico.

El patrimonio, el turismo y la gestión de los recursos locales El turismo patrimonial utiliza los recursos con cuatro consecuencias principales para la gestión. En primer lugar, aunque dichos recursos están rara vez en el suministro fijo absoluto que asumen algunos directores de recursos, sin embargo se pueden ver reducidos o dañados. Si sólo hay una única Venecia o un único "Muro de Adriano", entonces, se puede agotar de varias maneras. El espacio, por ejemplo, es obviamente finito y el espacio urbano todavía más. El daño puede ser directamente físico (los pies, la respiración y el calor humano de los usuarios) o indirecto mediante intrusión visual de los turistas en masa, la presencia necesaria de una amplia variedad de alojamientos o transportes secundario requerida por los turistas (Ashworth, 1989), o, más sutilmente, por un tipo de experiencia del usuario derivada de otra ("efecto expurgatorio"). Por otro lado, los recursos de patrimonio en general son, al contrario que los recurso naturales, creados por la demanda y, por lo tanto, más infinitamente reproducibles, reciclables y movibles (podemos crear, y de hecho hemos creado, más "Venecias" y "Muros de Adriano" mediante una oferta alternativa, centros de interpretación, experiencias virtuales y similares). Ningún nivel de consumo puede agotar o dañar las obras de Shakespeare o Mozart incluso

\section{Voces}

\section{Crecimiento insostenible}

\section{Ignacio Rodríguez Temiño \\ Arqueólogo}

De nuevo se nos propone hablar sobre patrimonio y desarrollo; de nuevo sin adjetivos que traten de explicar de qué patrimonio y de qué desarrollo se trata, aunque por el contexto se supone que nos preguntan sobre patrimonio cultural sensu lato y el desarrollo sostenible o sustentable o como quiera que se le denomine ahora. Si el contenido del patrimonio cultural (y del histórico como parte del mismo) no despierta debates acalorados, el desarrollo sostenible por el contrario está lejos de ser un elemento de discusión pacífica, sobre todo cuando -como es el caso de la línea mayoritaria de pensamiento- se asienta sobre la conversión de los bienes pertenecientes al patrimonio cultural en productos turísticos. Porque de eso se trata en definitiva. Y si alguien alberga dudas puede consultar el II Plan General de Bienes Culturales de la Consejería de Cultura de la Junta de Andalucia.

Me gustaria saber si alguien ha visto algún ejemplo de desarrollo sostenible en su entorno, por que yo no. Todo lo contrario. Los indices de aumento del consumo energético, indicador clave para medir la sostenibilidad de cualquier politica sectorial, se disparan y además lo normal es ver esos incrementos como muestra de bienestar. Luego qué razón hay para creer que se aplicarán políticas de sostenibilidad a la gestión del patrimonio cultural o, lo que viene a ser lo mismo, a dónde nos conduce incluir los bienes pertenecientes a este patrimonio en las estrategias de crecimiento económico. De momento, la respuesta es clara: la conversión de estos bienes en productos turisticos, preteriendo su valor educativo y volcando su gestión hacia los visitantes. Para la inmensa mayoria de los autores, provenientes tanto del ámbito de la gestión patrimonial como turística, las consecuencias positivas comportadas por el turismo se tradu- 
aunque Stratford o Salzburgo puedan ser utilizados en demasía.

En segundo lugar, muchos recursos y productos de patrimonio tienen las características de bienes públicos. No solamente están gestionados y financiados en el sector público para el "bien común", sino que habitualmente se puede acceder a ellos gratuitamente sin cargo para los usuarios que no pueden ser excluidos de ninguna forma. Así, el turismo no sólo utiliza los recursos creados para distintos fines; también compite con otros usos para dichos recursos. De hecho, no sólo es que no se les pueda negar a los usuarios de patrimonio la experiencia de edificios o paisajes urbanos históricos, sino que muchas de las experiencias de dicho patrimonio son de consumo obligatorio, lo deseen los consumidores o no. La gestión de dichos bienes públicos universalmente accesibles y gratuitos presenta una serie de dificultades fundamentales a las que se debe enfrentar la politica.

En tercer lugar, la situación de los recursos completamente fuera del sistema de contabilidad turística crea factores externos. Al flujo de costes y beneficios entre los productores y los consumidores de los productos de turismo patrimonial, se le deben añadir los costes y beneficios externos a este sistema de producción. El turismo impone enormes costes externos en los lugares en los que se produce, incluyendo los costes de oportunidad de desarrollos alternativos. De igual forma, los beneficios externos corresponden a los impuestos indirectos, instalaciones de ocio adicionales, imágenes promocionales de lugares mejoradas y muchos más. Ello plantea la cuestión de igualdad sectorial, espacial y temporal, en especial si los turistas de patrimonio u otros usuarios del patrimonio se aprovechan del sistema, si los costes y beneficios externos corresponden a los mismos individuos, agencias y lugares y si el plazo de incidencia de recepción de los cos- tes y beneficios es el mismo.

En cuarto lugar, y como resultado de lo anteriormente expuesto en gran parte, están las dificultades de organización. En términos simples, el paisaje histórico y cultural y los recursos bióticos han sido conservados y actualmente son gestionados predominantemente por agencias que no son las productoras de turismo $y$, frecuentemente, también por otros gestores de lugares distintos a los locales. Existen por tanto tres tipos de agencias, cada una de las cuales tienen un grupo de objetivos diferentes, estructuras de organización distintas, diversos instrumentos de gestión y prácticas de trabajo y, sin embargo, cada una está implicada en las decisiones de las demás. Cada una de estas características es sensible a la gestión, que se convierte así en el instrumento para solucionar el problema y crear o mantener la armonía una vez que las implicaciones de estas características han sido comprendidas y una vez que se han establecido claros objetivos. Para declarar que la solución reside en la gestión, hace falta especificar qué es lo que se va a gestionar, por quién y para quién.

\section{Resolución paradójica}

Nos encontramos ahora con algunas paradojas. Por un lado hay una conciencia creciente de que el desarrollo de una línea de producto diversificada, el bienestar económico de los lugares, y el mantenimiento de los patrimonios locales, pueden relacionarse en politicas comunes rentables para los tres grupos de actores, mientras que por otro lado parece bastante sorprendente que se sabe muy poco sobre dichas relaciones en detalle. Se asume, más que cuestionarse o explicarse, la idea de que existe una sim- cen en la generación de empleo y revitalización económica y, muy por encima de los riesgos inherentes a la concentración de personas en determinados monumentos históricos, la afección sobre éstos es igualmente saludable, hasta el punto de hacer depender la supervivencia del patrimonio cultural de su éxito turístico. Dadas las magnitudes del fenómeno turistico y la importancia económica de este sector en el PIB nacional, este llamamiento se ha convertido en una especie de "toque a rebato" entre las administraciones públicas de nuestra geografía.

No obstante, se ha hecho evidente, incluso para los más acérrimos defensores de las prácticas neoliberales, que el turismo no siempre es una bendición. Hoy parece que el núcleo del debate se ha centrado en una cuestión de equilibrio, traducible en cantidades de turistas, por encima de las cuales la visita se transforma en masificación. Teóricamente no presenta serias dificultades alcanzar soluciones de compromiso entre expertos, tanto en turismo como en conservación del patrimonio cultural, pero su aplicación real es bastante más difícil. La base de este desencuentro entre teoria y realidad viene por el rechazo que produce cualquier adopción de medidas, tendentes a calmar la afluencia de las golden hordes, entre los grandes tour operadores, que son quienes controlan el mercado y la dirección de los flujos turísticos, al que se suma también la población local más directamente afectada por una supuesta disminución de turistas. La inmediata politización de ese debate añade fuertes dosis de irracionalidad y oportunismo que hacen inviable cualquier asomo de solución (La Alhambra es un ejemplo palpable).

Quienes no piensan asi tampoco tienen claro cómo solventar el problema. Las posiciones más moderadas sostienen que la correcta unión entre turismo y patrimonio histórico sólo podrá optimizar sus efectos positivos, cuando en esa simbiosis predominen criterios de sostenibilidad física, social y medio ambiental. Desde esta óptica, aparecen nuevos conceptos como el de capacidad de carga, la teoria del ciclo vital de los destinos turísticos, o los análisis comparativos entre costes y beneficios, que permiten empezar a dar contenido a la idea de sostenibilidad, para que no sea un mero recurso dialéctico. Sin embargo, y a pesar de estas inmejorables intenciones, el acercamiento al $\gg$ 


\section{$070-071$ \\ Debate \\ e Investigación}

Historicidad, turismo y

política urbana: exploración

de la relación entre los tres

factores

\section{PH42 - Febrero 2003}

biosis automática y de armonía universal entre las tres partes. Las relaciones entre cada uno de los tres elementos, el patrimonio, el turismo y los lugares, plantea muchas cuestiones que pueden ser actualmente respondidas con confianza.

¿Por qué, y cómo, hacen los turistas uso del patrimonio? ¿Cuáles son las implicaciones para el patrimonio de su uso por parte de un turismo adicional? ¿Qué papel juega el patrimonio en los lugares y particularmente, cuáles son los impactos económicos y de otro tipo que producen el uso del patrimonio local por parte de los turistas en los distintos lugares? La gestión efectiva del turismo patrimonial para los objetivos del desarrollo local depende de las respuestas a todas estas preguntas.

El patrimonio es importante para el turismo pero esto no significa automáticamente que el turismo sea importante para el patrimonio. El turismo es altamente selectivo y el patrimonio tiene otros usos que podrian asociarse con prioridades mayores. Los intereses patrimoniales de los visitantes y el de los vecinos probablemente son bien distintos. El problema está a menudo en establecer las prioridades en el esfuerzo por la conservación nacional, entre los requisitos de un turismo extranjero lucrativo y los de los residentes, lo que plantea un dilema real sobre qué conservar y cómo interpretarlo.

Del mismo modo, el turismo patrimonial puede necesitar los recursos variados de la ciudad de patrimonio pero ello no significa que la ciudad necesite el turismo patrimonial. Aunque el turismo patrimonial es a menudo una útil actividad económica marginal (el "modelo de ganancia económica inesperada") y algunas veces el soporte principal para las economías locales, existen pocos casos en los que una ciudad o región haya colocado deliberadamente al turismo patrimonial como sector económico principal como compensación del fracaso económico existente en otro sector. Las condiciones para el éxito pueden enumerarse como imperativo económico con una gama severamente limitada de opciones alternativas; capacidad excedente especialmente de suelo, trabajo y servicios de apoyo; un conjunto de recursos capaz de transformarse en productos relevantes para mercados específicos; una situación afortunada con respecto a dicho mercado y también probablemente en el momento de la iniciativa. Dicha lista de precondiciones para conseguir un superá vit de beneficios económicos que supere los costes explica por qué el fracaso en el desarrollo del turismo patrimonial local es mucho más probable que el éxito.

De lo dicho anteriormente, queda claro que si vamos a gestionar un turismo patrimonial en un destino, de forma que satisfaga los objetivos de todos los intereses implicados, entonces necesitaremos una comprensión de algunas de las relaciones, un establecimiento de los objetivos y prioridades, un conjunto de instrumentos de intervención, ya sea para el uso de la tierra y control del desarrollo o para una gestión económica-fiscal y local o para una estructura organizacional capaz de llevar a cabo esas tareas en cada uno de los tres sectores. La postura pesimista es que no existe ninguna de ellas todavía: la visión optimista es que se podrían crear de una forma relativamente fácil. concepto de sostenibilidad no deja de presentar incertidumbres en el fondo mismo de la problemática, pues aunque se manifiestan de acuerdo con invertir las reglas del mercado (que la oferta prime sobre la demanda), no llegan a cuestionar la utilidad de aplicar el mercado al campo de los bienes culturales, quedándose en una crítica descafeinada.

Creo que por la vía anterior sólo se ponen parches, porque no se entra en la solución del problema. Para ello es necesario enfocar a la esencia del propio sistema; esto es, reconsiderar la propia teoria del valor. Como se ha encargado de demostrar la corriente de economía ecológica, sin entrar dentro de la teoría del valor resulta imposible atender al fondo del concepto de sostenibilidad. Para estos economistas, el denominado capital natural (entendido aqui como el propio recurso cultural) debe formar parte del valor, no siendo correcto hallarlo repercutiendo los costes de producción y reposición del producto, ya que se asume la eternidad de estos recursos. En el caso que nos ocupa, habida cuenta de la ausencia de contar con el coste de reposición de los bienes pertenecientes al patrimonio histórico (¿cuánto vale La Alhambra o cuánto dinero es preciso para atender a su restauración o simplemente para minimizar el deterioro ocasionado por la multitudinaria visita?) en la evaluación de los costes y, de forma general, en los presupuestos conceptuales sustentadores de estas politicas, el término "desarrollo sostenible" sigue haciendo abstracción del comportamiento despilfarrador de recursos del que hace gala la civilización industrial.

En consecuencia, la sostenibilidad en el sector turístico sólo puede entenderse como un deseo que presenta dificultades insuperables de aplicación, en la medida que la aproximación hacia su definición práctica nace de planteamientos reduccionistas que continúan mitificando el crecimiento económico. Por ello, se hace necesario cuando se hable de orientar hacia el turismo determinados recursos pertenecientes al patrimonio cultural, hacerlo desde un acercamiento mucho más atento a fijar indicadores que permitan cuantificar individualmente los efectos positivos y negativos provocados por él, algo que está aún por hacer. No debe olvidarse que España es un pais en que la gestión turistica guarda una suprema reverencia por las canti- 


\section{Bibliografía}

ASHWORTH, G.J. Tourism accommodation and the historic city. Built Environment, 1989, 15(2), 92-100

ASHWORTH, G.J. Planning for sustainable tourism. Town Planning Review, 63(3), 1992, 325-330

ASHWORTH, G.J. Managing the cultural tourist. In Ashworth, G.J and Dietvorst, A.G.J. (eds). Tourism and spatial transformations: implications for policy and planning. Wallingford: Cab international, 1995, 265-284

ASHWORTH, G.J.; TUNBRIDGE, J.E. The tourist-historic city. London: Belhaven, 1990

ASHWORTH, G.J.; TUNBRIDGE, J.E. Retrospect and prospect on the tourist-historic city. London: Elsevier, 2000

BERG, L. VAN DEN; BORG, J. VAN DER; MEER, J. VAN DER. Urban tourism: performance and strategies in eight European cities. London: Avebury, 1995

BIANCHINI, F. The role of cultural policies. In F. Bianchini and M. Parkinson (eds) Remaking European cities. Manchester: Manchester University Press, 1993

BONIFACE, P.; FOWLER, P.J. Heritage and tourism. London: Routledge, 1993
BORG J. VAN DEN; COSTA P.; GOTTI G. Tourism in European heritage cities. Annals of tourism research, 1996, 23(2), 30621

BORG, J. VAN DER. Tourism and urban development. Rotterdam: Faculty of Economics, Erasmus University of Rotterdam, 1990

BURGERS, J. Public space in the post-industrial city. In Ashworth G.J. \& A.G.J. Dietvorst (eds) Tourism and spatial transformation: implications for policy and planning. Wallingford: Cab international, 1995, 147-58

CHENG, J.R. Tourism: how much is too much?. Canadian geographer, 1990, 24(1)

DIETVORST A.G.J. Cultural tourism and time-space behaviour. In Ashworth, G.J. and P.J.Larkham (eds) Building a new heritage: tourism, culture and identity in the new Europe. London: Routledge, 1994, 69-89

DIETVORST A.G.J. Tourist behaviour and the importance of time-space analysis. In Ashworth G.J. \& A.G.J. Dietvorst (eds) Tourism and spatial transformation: implications for policy and planning. Wallingford: Cab international, 1995, 163-81

ENNEN, E. The groningen museum: urban heritage in fragments. International journal of heritage studies, 1997, 3(3), 144-56

EVANS, G. Cultural planning. London: Routledge, 2000 dades desde que, hace cuarenta años aproximadamente, se comenzasen las primeras politicas turisticas de manos de los gobiernos tecnocráticos del tardofranquismo. En la actualidad la situación no ha cambiado mucho: ya no hay foto del ministro del ramo con el/la "turista-un-millón" de cada temporada, pero la prensa diaria sigue dando el mismo mensaje por boca de los responsables politicos: torrentes de cifras recitadas como si de un mantra que nos trajese el bienestar se tratase. El éxito de la gestión sigue midiéndose por el monto absoluto de visitantes, como entonces.

En definitiva, no resulta fácil convencer de que si el turismo sea bueno para la conservación del patrimonio cultural, eso no significa que mucho de lo mismo sea mejor. Además, el creciente turismo cultural se siente aún atraido por tópicos, lo que provoca su concentración en pocos monumentos. Este hecho, dificil de gestionar con éxito por las administraciones responsables del patrimonio cultural, supone el principal talón de Aquiles de propuestas muy interesantes destinadas a que el turismo sea una auténtica experiencia cultural, una garantía de conserva- ción del patrimonio histórico, una plataforma excepcional para garantizar una divulgación digna y eficaz, que hiciese partícipe al público no experto de teorias e interpretaciones emanadas de los ambientes cientificos. Esta modalidad de turismo, sumamente minoritaria por el alto nivel educativo requerido, trata de recuperar el sentido del viajero frente al turista. Ambos términos no son sinónimos. El tránsito de uno a otro se mide por la progresiva devaluación de la acogida: el turismo se ha caracterizado por ir al espacio de otros, pero eludiendo su presencia, refugiado en infraestructuras específicas ajenas al lugar donde se encuentran. El principal problema es que los viajeros influyen muy levemente en el deseado crecimiento económico sostenido, que es lo buscado aunque el discurso oficial lo denomine "desarrollo sostenible". Y para obtener aumento del PIB necesitamos turistas, muchos turistas. 


\section{$072-073$}

\section{Debate}

e Investigación

Historicidad, turismo y

política urbana: exploración

de la relación entre los tres

factores

PH42 - Febrero 2003

GRABURN, N.H. The past in the present in Japan: nostalgia and neo-traditionalism in contemporary Japanese domestic tourism In Butler R and D.Pearce (eds) Change in tourism: people, places and processes. London: Routledge, 1995

GRAHAM, B.; ASHWORTH, G.J.; TUNBRIDGE, J.E. A geography of heritage: power, culture, economy. London: Arnold, 2000

HERBERT, D.T. (ED) Heritage, tourism and society. London: Cassell, 1995

HEWISON, R. The heritage industry: britain in a climate of decline. London: Methuen, 1987

HORNE, D. The great museum: the re-presentation of history. London: Pluto, 1984

HUGHES, H.; GRATTON, C. The economics of the culture industry. In Wynne (ed.) The culture industry: the arts in urban regeneration. Avebury: Aldershot, 1992

JANSEN-VERBEKE, M. Urban tourism: managing resources and visitors. In Wahab, S. and Pigram, J. (eds) Tourism, sustainability and growth. London: Routledge, 1997

LARKHAM, P. Conservation and the cities. London: Routledge, 1996

LAW, C.M. Urban tourism: attracting visitors to large cities. London: Mansell, 1993

LAW, C.M. Urban tourism. London: Routledge, 1995

LICHFIELD, N. Economics in conservation. Cambridge: Cambridge university press, 1988

LIM, H. Cultural strategies for revitalising the city: review and evaluation Regional studies, 27(6), 1993, 589-95

MASSER, I.; SVIDEN, 0.; WEGENER, M. What new heritage for which new Europe? Some contextual considerations, in Ashworth, G.J. and P.Larkham (eds) Building a new heritage: tourism, culture and identity in the new Europe. London: Routledge, 1994, pp 31-46

MERRIMAN, N. Beyond the glass case: the past, the heritage and the public in Britain. Leicester: Leicester university press, 1991

MINISTERIE WVC. Investeren in cultuur: nota cultuurbeleid
1993-6. Sdu The Hague, 1992

MOSSETTO, G. The economics of the cities of art: a tale of two cities, Nota di lavoro, 91.10. Venice: Dept. of economics, University of Venice, 1991

OOSTERMAN, J. Welcome to the pleasure dome: play and entertainment in urban public space: the example of the sidewalk cafe, Built environment, 18(2), 1993, 155-65

PAGE, S. J. Managing tourism in a small historic town. Town and country planning, 1992, 208-11

PAGE, S.J. Urban tourism. London: Routledge, 1995

PFAFFLIN, G. Concern for tourism. Annals of tourism research, 9, 1987, 576-88

PRENTICE, R. Tourism and heritage attractions. London: Routledge, 1993

PRENTICE, R. Tourism as experience, tourists as consumers: insight and enlightenment. Inaugural lecture. Edinburgh: Queen Margaret College, 1996

ROBINSON, M.; EVANS, N.; CALLAGHAN, P. (EDS). Tourism and culture towards the 21st century. Newcastle: University of Northumbria, 1997

SILBERBERG, T. Cultural tourism and business opportunities for museums and heritage sites. Tourism management, 16(5), 1995, 361-65

SINCLAIR, M.T.; STABLER, M. The economics of tourism. London: Routledge, 1997

SMITH, V.L. (ED). Hosts and guests: the anthropology of tourism. Oxford: Blackwell, 1977

SNEDCOF, H. Cultural facilities in multi-use developments. Washington: Urban land, 1985

STABLER, M. Are heritage and tourism compatible: an economic evaluation of their role in urban regeneration. In Robinson, M., N.Evans and P.Callaghan (eds) Tourism and culture towards the 21st century. Newcastle: University of Northumbria, 1996

TIESDELL, S.; OC, T.; HEATH, T. Revitalising historic urban quarters. Oxford: Architectural press, 1996

TURNER, L.J.; ASH, J. The golden horde: international tourism and the pleasure periphery. London: Constable, 1976

URRY, J. Europe, tourism and the nation-state. In Cooper, C.P. and Lockwood, A. (eds) Progress in tourism, recreation and hospitality management. Wiley, Chichester, 1994, 89-98

VERGO, P. (ED). The new museology. London: Reaktion books, 1989

WHEELER, B. Tourisms troubled times. Tourism Management, 1991, 12(2)

WHITT. Mozart in the metropolis. Urban affairs quarterly, 1987, $15-36$

WYNNE, D. (ED). The culture industry: the arts in urban rege- 